\title{
Existing data sources for clinical epidemiology: the Danish Quality Database of Mammography Screening
}

\author{
Vivian Langagergaard' \\ Jens P Garne ${ }^{2}$ \\ Ilse Vejborg ${ }^{3}$ \\ Walter Schwartz ${ }^{4}$ \\ Martin Bak $^{5}$ \\ Anders Lernevall' \\ Nikolaj B Mogensen ${ }^{6}$ \\ Heidi Larsson ${ }^{7}$ \\ Berit Andersen' \\ Ellen M Mikkelsen ${ }^{7}$ \\ 'Department of Public Health \\ Programs, Randers Hospital, Randers, \\ Denmark; ${ }^{2}$ Department of Breast \\ Surgery, Aalborg Hospital, Aalborg, \\ Denmark; ${ }^{3}$ Diagnostic Imaging \\ Center, Copenhagen University \\ Hospital, Rigshospitalet, Copenhagen, \\ Denmark; ${ }^{4}$ Center of Mammography, \\ ${ }^{5}$ Department of Pathology, Odense \\ University Hospital, Denmark; \\ ${ }^{6}$ Department of Radiology, Ringsted \\ Hospital, Ringsted, Denmark; \\ ${ }^{7}$ Department of Clinical Epidemiology, \\ Aarhus University Hospital, Aarhus, \\ Denmark
}

This article was published in the following Dove Press journal:

Clinical Epidemiology

13 March 2013

Number of times this article has been viewed
Abstract: The Danish Quality Database of Mammography Screening (DKMS) was established in 2007, when screening was implemented on a nationwide basis and offered biennially to all Danish women aged 50-69 years. The primary aims of the database are to monitor and evaluate the quality of the screening program and - after years of follow-up - to evaluate the effect of nationwide screening on breast cancer-specific mortality. Here, we describe the database and present results for quality assurance from the first round of national screening. The steering committee for the DKMS defined eleven organizational and clinical quality indicators and standards to monitor the Danish breast cancer screening program. We calculated the relevant proportions and ratios with $95 \%$ confidence intervals for each quality indicator. All indicators were assessed on a national and regional level. Of 670,039 women invited for mammography, $518,823(77.4 \%)$ participated. Seventy-one percent of the women received the result of their mammography examination within 10 days of screening, and $3 \%$ of the participants were recalled for further investigation. Among all detected cancers, $86 \%$ were invasive cancers, and the proportion of women with node negative cancer was $67 \%$. There were $36 \%$ women with small cancers, and the ratio of surgery for benign lesions to malignant lesions was 1:6.3. A total of $80 \%$ of women with invasive cancers were treated with breast conserving therapy. Screening interval and interval cancers were not relevant in the first round, and data regarding radiation dose were not available at the time of evaluation. Overall, the quality indicators showed satisfactory quality in the first round of national breast cancer screening in Denmark. The DKMS is a potentially valuable tool for improving quality and conducting research in the field of breast cancer screening.

Keywords: screening, breast cancer, quality indicators

\section{Introduction}

Breast cancer is the most common female cancer in Denmark, with approximately 4500 women diagnosed each year. ${ }^{1}$ In 2006-2010, breast cancer accounted for $28 \%$ of all incident cancers and 16\% of all cancer deaths among Danish women. ${ }^{2}$

Mammography screening of asymptomatic women has the potential to detect breast cancer at an early stage and improve prognosis. An overview of the randomized trials in Sweden showed that, after a follow-up period of 5 to 13 years, breast cancer mortality was reduced 29\% among women aged 50-69 years who were invited for breast cancer screening. ${ }^{3}$ Numerous studies from different countries have concluded that organized mammography screening reduces breast cancer mortality, ${ }^{4-6}$ though the extent of the reduction has been debated. ${ }^{7,8}$

In Denmark, organized population-based breast cancer screening with mammography began in Copenhagen in 1991, in the county of Funen in 1993, and in
Correspondence: Vivian Langagergaard Centre for Public Health and Quality Improvement, Olof Palmes Allé 15-17, DK-8200 Aarhus N, Denmark

Tel +45 78 4l 4245

Email vivlan@rm.dk 
the municipality of Frederiksberg in $1994 .^{9}$ These three programs covered approximately $20 \%$ of the Danish female population aged 50-69 years. ${ }^{9}$ Mammography screening was introduced in Bornholm in 2001 and in 2004 in the county of West Zealand. By law, breast cancer screening was implemented on a nationwide basis at the end of 2007 and offered free of charge every 2 years to all Danish women aged 50-69 years. ${ }^{10}$

The overall goal of a breast cancer screening program is to reduce breast cancer-specific mortality and morbidity with as few negative side effects as possible. To achieve this goal, high clinical and organizational standards are necessary in the screening program, as well as in the ensuing diagnostic and treatment processes. ${ }^{9}$ The effect of screening on mortality cannot be evaluated until several years after the implementation of the program. Thus, continuous monitoring of the quality of all aspects of the screening program is essential for securing a high standard. Here, we describe the Danish Quality Database of Mammography Screening (DKMS) and present the results for quality assurance from the first round of national screening.

\section{DKMS}

In 2007, the Danish Regions appointed a steering committee for the DKMS to collect data and manage quality assurance. The committee has developed guidelines concerning organizational requirements for the Danish screening program ${ }^{9}$ and defined eleven quality indicators and associated standards based on the fourth edition of the European Guidelines for Quality Assurance in Breast Cancer Screening and Diagnosis. ${ }^{11}$ The screening program and establishment of the quality database are financed by the Danish health care system. The primary aims of the quality database are to monitor and evaluate the quality of the screening program and evaluate, after years of follow-up, the effect of nationwide screening on breast cancer-specific mortality.

\section{Organization of the screening program}

Every 2 years, all Danish women aged 50-69 years receive a letter with an invitation for a mammography. The five regions in Denmark, which all perform mammography screening, each have their own booking systems and send personal invitations to the women, based on updated population data from the Civil Registration System. ${ }^{12}$ The women can decline participation or rejoin the screening program at any time. The invitation includes a suggested time for an appointment as well as an information leaflet about mammography screening.
A questionnaire concerning issues, such as treatment with estrogen replacement therapy, previous breast surgery, and self-detected breast abnormalities, is enclosed with the invitation or presented at the time of screening. This information is forwarded electronically to the radiologists who evaluate the mammogram images. Two images are taken of each breast at each screening session. The images are read independently by two radiologists, at least one of whom is an experienced screening radiologist. ${ }^{9}$ Any suspicious abnormalities detected by screening lead to further diagnostic investigation. Clinical examination, imaging, needle biopsy, and/or surgery are central to the diagnostic process. The diagnostic investigations of any abnormalities detected by screening adhere to the Danish Breast Cancer Cooperative Group's guidelines concerning diagnosis. ${ }^{13}$

\section{Population in the first screening round}

The first nationwide round of screening in Denmark covered the five regions over slightly different time periods. The first women were invited in mid-2007, and the last women were screened in December 2010. ${ }^{14}$ Women who specifically requested not to participate in earlier local breast cancer screening programs conducted in some areas of Copenhagen, Zealand, and Southern Denmark were not invited to join the nationwide screening program. In the Capital Region of Denmark, women who had been operated on for breast cancer within the last 18 months were not invited. A total of 670,039 women were invited during the first round of screening, and 518,823 (77.4\%) participated in the screening. Women who were invited more than once because they moved to another region during the study period were only counted once $(n=1289) .{ }^{14}$

Table 1 presents the proportion of invited women, according to age, who participated in the first round of the Danish screening program. Women aged 65-69 years were the least likely to participate in the screening. The same pattern was seen in each region except for the North Denmark Region (data not shown), where women aged 50-54 years were the least likely to participate (participation: 58.7\%, 95\% confidence interval 58.0-59.3). In all regions, the mean age of the women who participated in screening was 59 years old (data not shown).

\section{Data and data linkage}

Data from the booking system (civil registration number, screening round, date of invitation, date of screening, and date of sending the screening result to the woman) in each of 
Table I Proportion of invited women who participated in the first round of nationwide mammography screening

\begin{tabular}{llll}
\hline $\begin{array}{l}\text { Age group } \\
\text { (years) }\end{array}$ & $\begin{array}{l}\text { Number of } \\
\text { screened women }\end{array}$ & $\begin{array}{l}\text { Number of } \\
\text { invited women }\end{array}$ & $\begin{array}{l}\text { Proportion } \\
(95 \% ~ C l)\end{array}$ \\
\hline$<50^{\mathrm{a}}$ & 12 & 36 & $33.3(18.6-51.0)$ \\
$50-54$ & 140,558 & 182,212 & $77.1(76.9-77.3)$ \\
$55-59$ & 133,167 & 167,713 & $79.4(79.2-77.3)$ \\
$60-64$ & 140,113 & 178,345 & $78.6(78.4-78.8)$ \\
$65-69$ & 103,084 & 138,890 & $74.2(74.0-74.4)$ \\
$>69^{\mathrm{a}}$ & 1889 & 2843 & $66.4(64.7-68.2)$ \\
Total & 518,823 & 670,039 & $77.4(77.3-77.5)$ \\
\hline
\end{tabular}

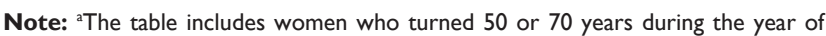
invitation to screening.

Abbreviation: $\mathrm{Cl}$, confidence interval.

the five Danish regions are transferred electronically to the DKMS. The data are registered and validated by the DKMS in an ongoing process, and the completeness of data in the DKMS is almost $100 \% .^{14}$

Data regarding biopsies are reported online to the Danish National Pathology Registry (DNPR), which contains detailed records of all cytological and histological specimens analyzed in Denmark since $1997 .{ }^{15}$ Reporting to the DNPR is based on national guidelines for uniform registration. Data are updated on a daily basis and are of high quality and completeness. ${ }^{15}$ From this registry, the DKMS retrieves primary outcome data [breast cancer, ductal carcinoma in situ (DCIS) lesions, tumor size, and node negative cancers] for all women in the cohort.

Information on the results of mammography screening (normal/abnormal), surgery for malignant and benign lesions, and the number of women with breast cancer treated with breast conserving therapy is retrieved from the National Registry of Patients. This registry contains detailed information, including the civil registration number, date of admission and discharge, and up to 20 discharge diagnoses and procedures for all patients admitted to a somatic hospital in Denmark since 1977, including all outpatient contacts since $1995 .{ }^{16}$ To calculate the number of interval cancers as a proportion of the underlying expected breast cancer incidence rate in the absence of nationwide screening, information about the incidence of breast cancer in the background population in 2006 is ascertained from the Danish Cancer Registry. ${ }^{17}$

Data from all sources are linked using the civil registration number, a unique ten digit personal identification number assigned to each Danish resident. The Civil Registration System is continuously updated with information on all Danish residents regarding vital status, change of address, and emigration. ${ }^{12}$

\section{Quality indicators}

The eleven organizational and clinical quality indicators and standards defined by the DKMS steering committee to monitor the Danish breast cancer screening program are participation, screening interval, time to result, radiation dose, recall, interval cancers, invasive tumors, node negative cancers, small cancers, breast conserving therapy, and ratio of surgery for benign to malignant lesions.

\section{Organizational quality indicators Participation}

For screening to achieve an effect on breast cancer morbidity and mortality, high participation is important. The proportion of invited women who participate in mammography screening, excluding women who have resigned from the program, has a standard value of $>75 \%$. In contrast, the proportion of all women aged 50-69 years who reside in Denmark at the start of the screening round and participate in the screening has no set standard.

\section{Screening interval}

Monitoring the screening interval is an important quality control factor for increasing the detection of tumors at an early stage. In Denmark, the interval between screens has been set to 24 months ( \pm 3 months), which is in accordance with the majority of other population-based screening programs. ${ }^{9}$ The interval is a measure of the number of women who are re-invited to screening within 24 months ( \pm 3 months) compared to all women re-invited to screening. The standard value for this indicator is $\geq 98 \%$.

\section{Time from screening to result}

Waiting for results may induce unnecessary anxiety. The number of women who received their screening result $\leq 10$ working days after screening compared to the total number of women who were screened has a standard value of $>95 \%$. Women without a registered date for their results in the first screening round were excluded from the present analysis.

\section{Clinical quality indicators Radiation dose}

Technical quality control will ensure that the radiologist obtains the best possible images using the lowest possible radiation dose. ${ }^{11}$ Data are reported as the mean glandular dose, which is the radiation dose measured on a $45 \mathrm{~mm}$ polymethylmethacrylate test phantom corresponding to a $53 \mathrm{~mm}$ standard breast. ${ }^{14}$ The radiation dose should be measured once a week on all technical equipment used 
for mammography screening. ${ }^{14}$ The standard value for this indicator is $<2.0 \mathrm{mGy}$.

\section{Recall}

Any suspicious abnormalities detected on mammogram led to a recall for additional diagnostic investigation. To reduce cost and minimize anxiety, the number of recalled women without cancer (false positives) should be kept as low as possible with due respect to the detection rate. The proportion of all screened women recalled for further examination (including true and false positives) has a standard value of $<5 \%$ in the first screening round (prevalent and incident cases) and $<3 \%$ in subsequent screening rounds (incident cases).

\section{Interval cancers}

A screening program cannot identify all malignant tumors at a given time. ${ }^{9}$ This indicator describes the number of over-looked, fast growing, or radiologically undetectable invasive malignant tumors at the time of screening and reports the number of women diagnosed with invasive malignant tumors in the 2 year interval after the women tested negative at screening, compared to the occurrence of breast cancer in the background population in the absence of screening (in 2006). The standard value for this indicator is $<30 \%$ ( $\leq 12$ months after screening) and $<50 \% \quad 12-24$ months months after screening).

\section{Invasive breast tumors}

A potential negative effect of breast cancer screening is overdiagnosis, which is defined as the identification of cancers that would not have been found during the lifetime of the woman in the absence of screening. ${ }^{9}$ To minimize the risk of over-diagnosis and over-treatment, the relative number of DCIS cases identified in a screening program should not exceed 20\%, and it should not be less than 10\%; 30\%-50\% of DCIS lesions are estimated to progress to invasive cancer. ${ }^{9}$ The number of women with invasive cancers compared to the total number of women diagnosed with cancer (including DCIS) due to the organized screening program has a standard value of $80 \%-90 \%$.

\section{Node negative cancers}

Node status is a prognostic factor for breast cancer survival. Detecting cancer at an early stage increases the likelihood of negative axillary status. The number of women with invasive node negative cancers compared to the total number of women operated on for invasive breast cancer due to the organized screening program has a standard value of
$>70 \%$ during the first screening round (prevalent and incident cases) and $>75 \%$ during subsequent screening rounds (incident cases).

\section{Small cancers}

Tumor size is a prognostic factor, and the percentage of small cancers is a principal radiological quality indicator. The number of women with an invasive cancer $\leq 1 \mathrm{~cm}$ compared to the total number of women operated on for invasive cancer due to the organized screening program has a standard value of $\geq 25 \%$ during the first screening round (prevalent and incident cases) and $\geq 30 \%$ during subsequent screening rounds (incident cases).

\section{Surgery for benign versus malignant lesions}

The ratio of the number of surgeries for benign lesions to the number of surgeries for malignant lesions is an indicator of the combined quality of the diagnostic team consisting of radiologists, surgeons, and pathologists. ${ }^{9}$ The number of women with benign lesions who are referred to surgery should be kept as low as possible without compromising the detection of malignant lesions. The ratio of the number of women with benign lesions who are referred to surgery and the number of women with malignant lesions (including DCIS) who are referred to surgery has a standard value of $\leq 1: 4$.

\section{Breast conserving therapy}

Mammography screening leads to the detection of cancer at an early stage, increasing the potential for breast conserving therapy. The number of women diagnosed with invasive cancer and treated with breast conserving therapy compared to the total number of women operated on for invasive breast cancer due to the organized screening program has a standard value of $>50 \%$ during the first screening round (prevalent and incident cases) and $>60 \%$ during subsequent screening rounds (incident cases).

\section{Data analysis}

To evaluate whether the screening program performed as desired, we calculated the relevant values and 95\% confidence intervals for each quality indicator in accordance with the European Guidelines for Quality Assurance in Breast Cancer Screening and Diagnosis. ${ }^{11}$ All indicators were assessed on a national and regional level.

\section{First results}

Tables 2 and 3 present the organizational and clinical quality indicators based on the first screening round in Denmark, 
Table 2 Organizational quality indicators based on the first round of nationwide mammography screening in Denmark

\begin{tabular}{|c|c|c|c|}
\hline Organizational quality indicators & $\begin{array}{l}\text { Number } \\
\text { of women }\end{array}$ & $\begin{array}{l}\text { Proportion } \\
(95 \% \mathrm{Cl})\end{array}$ & Standard ${ }^{a}$ \\
\hline \multicolumn{4}{|c|}{ Proportion of invited women who participated in the screening program } \\
\hline Screened women/all women invited & & & $>75 \%$ \\
\hline Capital Region of Denmark & $139,987 / 191,279$ & $73.2 \%(73.0-73.4)$ & \\
\hline Region Zealand & $91,113 / 111,522$ & $81.7 \%(81.5-81.9)$ & \\
\hline North Denmark Region & $48,980 / 75,260$ & $65.1 \%(64.7-65.4)$ & \\
\hline Central Denmark Region & $|15,7| 7 / 149,817$ & $77.2 \%(77.0-77.5)$ & \\
\hline Region of Southern Denmark & $|23,026 /| 42,16 \mid$ & $86.5 \%(86.4-86.7)$ & \\
\hline Total & $518,823 / 670,039$ & $77.4 \%(77.3-77.5)$ & \\
\hline \multicolumn{4}{|c|}{ Proportion of women in the target population who participated in screening } \\
\hline Screened women/women living in the region, & & & Not defined \\
\hline \multicolumn{4}{|l|}{ aged $50-69$ years, January I, 2010} \\
\hline Capital Region of Denmark & $139,987 /|95,0| 3$ & $71.8 \%(71.6-72.0)$ & \\
\hline Region Zealand & $91,113 / 112,249$ & $81.2 \%(80.9-81.4)$ & \\
\hline North Denmark Region & $48,980 / 73,861$ & $66.3 \%(66.0-66.7)$ & \\
\hline Central Denmark Region & $115,7 \mid 7 / 149,266$ & $77.5 \%(77.3-77.7)$ & \\
\hline Region of Southern Denmark & $\mid 23,026 / 152,057$ & $80.9 \%(80.7-8 I .1)$ & \\
\hline Total & $518,823 / 682,446$ & $76.0 \%(75.9-76.1)$ & \\
\hline \multicolumn{4}{|l|}{ Time from screening to result } \\
\hline Women who received their result $\leq 10$ days & & & $>95 \%$ \\
\hline \multicolumn{4}{|l|}{ after screening/all women screened ${ }^{b}$} \\
\hline Capital Region of Denmark & $30,345 /|39,84|$ & $21.7 \%(21.5-21.9)$ & \\
\hline Region Zealand & 7I,778/90,931 & $78.9 \%(78.7-79.2)$ & \\
\hline North Denmark Region & $27,373 / 40,996$ & $66.8 \%(66.3-67.2)$ & \\
\hline Central Denmark Region & ||$|, 9||/| \mid 5,708$ & $96.7 \%(96.6-96.8)$ & \\
\hline Region of Southern Denmark & $121,700 / 123,006$ & $98.9 \%(98.9-99.0)$ & \\
\hline Total & $363,107 / 510,482$ & $71.1 \%(71.0-71.3)$ & \\
\hline
\end{tabular}

Notes: astandards are defined by the steering committee for the Danish Quality Database of Mammography Screening (DKMS) based on the fourth edition of the European Guidelines for Quality Assurance in Breast Cancer Screening and Diagnosis;" '834I women were excluded because the date of result was undisclosed.

Abbreviation: $\mathrm{Cl}$, confidence interval.

excluding screening interval, interval cancers, and radiation dose. The screening interval and interval cancers were not relevant to the first round, and data regarding radiation dose were not available at the time of evaluation. An effort is currently being made to ensure that radiation dose is measured on a weekly basis and reported to the DKMS.

Regional differences were found in the proportion of women who participated in the screening (Table 2) but, with the exception of the Danish Capital Region (73\%) and the North Denmark Region (65\%), participation in all regions met the standard of $>75 \%$. Only $71 \%$ of the women received the result of their mammography examination within 10 days of screening, and the regional differences were large. The long time for a response reflects the fact that the screening program was undergoing implementation and that only screening radiologists read the mammogram images in order to achieve high quality. Time to response is expected to be reduced when the program is fully implemented.

Only $3 \%$ of the participants were recalled for further investigation, and all regions fulfilled the standard (Table 3). Among all detected cancers (including DCIS), 86\% were invasive cancers and, with the exception of the North Denmark Region (92.2\%), all regions complied with the standard. The proportion of women with node negative cancer was $67 \%$, which did not meet the standard of $>70 \%$ based on the European Guidelines. However, these guidelines were written before the implementation of the sentinel lymph node technique, which facilitates the identification of lymph node metastases. A previous study found that the introduction of sentinel lymph node dissection in Denmark resulted in a stage migration of $4 \%$ due to the identification of more micrometastases. ${ }^{18}$

All regions fulfilled the standard for the proportion of small cancers. However, information on tumor size was missing for 835 women (21.3\%), who were excluded from the analysis. Initiatives have been launched to increase the registration of tumor size, which is a new variable in the DNPR.

The ratio of surgery for benign lesions to malignant lesions was fulfilled by all regions except the North Denmark Region (ratio 1:3.6). In addition, a total of $80 \%$ of women with invasive cancers were treated with breast conserving therapy, which means that the standard of $>50 \%$ was 
Table 3 Clinical quality indicators based on the first round of nationwide mammography screening in Denmark

\begin{tabular}{|c|c|c|c|}
\hline Clinical quality indicators & $\begin{array}{l}\text { Number } \\
\text { of women }\end{array}$ & $\begin{array}{l}\text { Proportion or ratio } \\
(95 \% \mathrm{Cl})\end{array}$ & Standarda \\
\hline \multicolumn{4}{|l|}{ Recall } \\
\hline Recalled women/all women screened & & & $<5 \%$ \\
\hline Capital Region Denmark & $3982 / 139,987$ & $2.8 \%(2.8-2.9)$ & \\
\hline Region Zealand & $2477 / 91,113$ & $2.7 \%(2.6-2.8)$ & \\
\hline North Denmark Region & $2351 / 48,980$ & $4.8 \%(4.6-5.0)$ & \\
\hline Central Denmark Region & $3456 / 115,717$ & $3.0 \%(2.9-3.1)$ & \\
\hline Region of Southern Denmark & $3165 / 123,026$ & $2.6 \%(2.5-2.7)$ & \\
\hline Total & $|5,43| / 5 \mid 8,823$ & $3.0 \%(2.9-3.0)$ & \\
\hline \multicolumn{4}{|l|}{ Invasive breast tumors } \\
\hline Women with invasive cancers $/$ all women with cancer (including DCIS) & & & $\geq 80 \%$ and $\leq 90 \%$ \\
\hline Capital Region of Denmark & $1059 / 1235$ & $85.7 \%(83.7-87.7)$ & \\
\hline Region Zealand & $753 / 882$ & $85.4 \%(82.9-87.6)$ & \\
\hline North Denmark Region & $400 / 434$ & $92.2 \%(89.2-94.5)$ & \\
\hline Central Denmark Region & $963 / 1096$ & $87.9 \%(85.8-89.7)$ & \\
\hline Region of Southern Denmark & $933 / 1110$ & $84.1 \%(81.8-86.2)$ & \\
\hline Total & $4108 / 4757$ & $86.4 \%(85.3-87.3)$ & \\
\hline \multicolumn{4}{|l|}{ Node negative cancers } \\
\hline Women with node negative invasive carcinomas/women operated & & & $>70 \%$ \\
\hline \multicolumn{4}{|l|}{ on for invasive carcinomas ${ }^{c}$} \\
\hline Capital Region of Denmark & $682 / 1008$ & $67.7 \%(64.7-70.5)$ & \\
\hline Region Zealand & $500 / 717$ & $69.7 \%(66.2-73.1)$ & \\
\hline North Denmark Region & $237 / 385$ & $61.6 \%(56.5-66.4)$ & \\
\hline Central Denmark Region & $590 / 876$ & $67.4 \%(64.1-70.5)$ & \\
\hline Region of Southern Denmark & $605 / 892$ & $67.8 \%(64.6-70.9)$ & \\
\hline Total & $26 \mid 4 / 3878$ & $67.4 \%(65,9-68,9)$ & \\
\hline
\end{tabular}

\section{Small cancers}

Women with invasive carcinomas $\leq \mathrm{I} \mathrm{cm} /$ women operated on for invasive carcinomas ${ }^{d}$

Capital Region of Denmark

Region Zealand

North Denmark Region

Central Denmark Region

Region of Southern Denmark

Total

Ratio of surgery for benign versus malignant lesions ${ }^{\mathbf{e}}$

Women operated on for benign lesions/women operated on

for malignant lesions (incl DCIS) ${ }^{f}$

Capital Region of Denmark

Region Zealand

North Denmark Region

Central Denmark Region

Region of Southern Denmark

Total

Breast conserving therapy

Women with invasive carcinomas treated with breast conserving

therapy/women operated on for invasive carcinomas

Capital Region of Denmark

Region Zealand

North Denmark Region

Central Denmark Region

Region of Southern Denmark

$85.7 \%(83.7-87.7)$
$85.4 \%(82.9-87.6)$
$92.2 \%(89.2-94.5)$
$87.9 \%(85.8-89.7)$
$84.1 \%(81.8-86.2)$
$86.4 \%(85.3-87.3)$

$67.7 \%(64.7-70.5)$
$69.7 \%(66.2-73.1)$
$61.6 \%(56.5-66.4)$
$67.4 \%(64.1-70.5)$
$67.8 \%(64.6-70.9)$
$67.4 \%(65,9-68,9)$

$\geq 25 \%$

$\begin{array}{ll}279 / 7 \mid 8 & 38.9 \%(35.3-42.5) \\ 274 / 717 & 38.2 \%(34.6-41.9) \\ 66 / 228 & 28.9 \%(23.2-35.3) \\ 196 / 591 & 33.2 \%(29.4-37.1) \\ 312 / 840 & 37.1 \%(33.9-40.5) \\ 1127 / 3094 & 36.4 \%(34.7-38.1)\end{array}$

Ratio: $\leq \mathrm{I}: 4$

\begin{tabular}{|c|c|}
\hline $131 / 1196$ & I:9.1 \\
\hline II9/857 & $\mathrm{I}: 7.2$ \\
\hline $119 / 430$ & $1: 3.6$ \\
\hline I78/1033 & $\mathrm{I}: 5.8$ \\
\hline $198 / 1147$ & $\mathrm{I}: 5.8$ \\
\hline $745 / 4663$ & $1: 6.3$ \\
\hline
\end{tabular}

Total

$>50 \%$

Notes: aStandards for each quality indicator are defined by the steering committee for the Danish Quality Database of Mammography Screening (DKMS) based on the fourth edition of the European Guidelines for Quality Assurance in Breast Cancer Screening and Diagnosis;" includes women diagnosed with invasive carcinomas, sarcomas, or malignant lymphomas. Data extracted from the DNPR; ‘5I women were excluded due to missing information on axillary status. Data extracted from the DNPR; 835 women were excluded due to missing information on tumor size. Data extracted from the DNPR; eassessed as a proportion (women operated on for benign lesions/all women operated on for breast tumors) and with a standard of $\leq 20 \%$, the proportions (95\% Cl) were: 9.9\% (8.3-I I.6), I2.2\% (I0.2-I4.4), 2I.7\% (I8.3-25.4), 14.7\% (I2.8-I6.8), 14.7\% (I2.9-I6.7), and I3.8\% (I2.9-I4.7) for Capital Region of Denmark, Region Zealand, North Denmark Region, Central Denmark Region, Region of Southern Denmark, and all of Denmark, respectively; fdata on women operated on for a malignant lesion were extracted from the NRP. The number is not equal to the number of invasive carcinomas registered in the DNPR.

Abbreviations: Cl, confidence interval; DCIS, ductal carcinoma in situ; DNPR, Danish National Pathology Registry; NRP, National Registry of Patients. 
met easily. The high incidence of breast conserving therapy can be explained by changes in surgical practice.

\section{Conclusion}

Overall, the quality indicators showed satisfactory quality in the first round of national breast cancer screening in Denmark. The DKMS is a potentially valuable tool for improving quality and conducting research in the field of breast cancer screening. However, the data have some limitations. Data from the first screening round did not include information on the screening interval or interval cancers due to the short follow-up time. The fact that local screening programs were conducted in some areas of Denmark before the nationwide screening program was implemented is a limitation for comparisons between regions, as the screening program will detect more prevalent cases in some regions than in others. Comparing results from the first screening round to results from the second round, where predominantly incident cases are detected, may also be difficult.

The strengths of the DKMS include a large sample size that increases every year and detailed registration of the quality indicators with regular quality assessment. Breast cancer screening is free of charge and all Danish women between 50 and 69 years of age are invited to participate, which reduces potential selection bias. In addition, we are able to obtain nearly complete follow-up for the main outcomes: invasive breast tumors, node negative cancers, small cancers, breast conserving therapy, and mortality from nationwide registries. Thus, women who decline participation in the screening program or drop out after a few screening rounds can be compared to women who stay in the program in regards to breast cancer-specific morbidity and mortality.

In this baseline study, we did not adjust for potential confounders, such as the age and socioeconomic background of the participants, which may differ between regions. However, we found no differences in the mean age of screening participants in the five regions. Thus, we assume no confounding occurred due to age. In future studies based on the DKMS, data on different exposures, such as comorbidity, demographic variables, and socioeconomic status, can be retrieved from other Danish registries and enable the researchers to control for several potential confounders in multivariable analyses.

\section{Access for other researchers}

The data are held by the DKMS at Competence Center North, Department of Clinical Epidemiology, Aarhus University Hospital. The DKMS home page can be accessed on the web via: http://kea.au.dk/kliniskkvalitet/kliniskedatabaser/ danskkvalitetsdatabaseformammografiscreening/. We encourage interested parties to contact the chairman of DKMS, senior consultant Jens Peter Garne at jpg@ rn.dk or senior researcher Ellen M Mikkelsen at em@ dce.au.dk.

\section{Disclosure}

The authors report no conflicts of interest in this work.

\section{References}

1. Danish Breast Cancer Cooperative Group. [Performance Indicator Report 2010]. Copenhagen: Danish Breast Cancer Cooperative Group; 2010. Available from: http://www.dbcg.dk/PDF\%20Filer/ Kvalitetsindikatorrapport\%202010_Webversion.pdf. Accessed July 21, 2012.

2. Kræftstatistik: Nøgletal og figurer Danmark - Bryst [Cancer Statistics: Key Facts and Figures Denmark - Breast]. Copenhagen: NORDCAN, Association of the Nordic Cancer Registries, Danish Cancer Society; 2013. Available from: http://www-dep.iarc.fr/NORDCAN/DK/StatsFact. asp? cancer $=180 \&$ country $=208$. Accessed February 19, 2013. Danish.

3. Nyström L, Rutquist LE, Wall S, et al. Breast cancer screening with mammography: overview of Swedish randomised trials. Lancet. 1993;341(8851):973-978.

4. Olsen AH, Njor SH, Vejborg I, et al. Breast cancer mortality in Copenhagen after introduction of mammography screening: cohort study. BMJ. 2005;330(7485):220.

5. Otto SJ, Fracheboud J, Verbeek AL, et al. Mammography screening and risk of breast cancer death: a population-based case-control study. Cancer Epidemiol Biomarkers Prev. 2012;21(1):66-73.

6. Independent UK Panel on Breast Cancer Screening. The benefits and harms of breast cancer screening: an independent review. Lancet. 2012;380(9855):1778-1786.

7. Jørgensen KJ, Keen JD, Gøtzsche PC. Is mammographic screening justifiable considering its substantial overdiagnosis rate and minor effect on mortality? Radiology. 2011;260(3):621-627.

8. Bleyer A, Welch HG. Effect of three decades of screening mammography on breast-cancer incidence. $N$ Engl J Med. 2012;367(21): 1998-2005.

9. Vejborg I, Mikkelsen E, Garne JP, et al. Mammography screening in Denmark. Dan Med Bull. 2011;58(6):C4287.

10. [The Danish Health Legislation] [webpage on the Internet]. Indenrigs- og Sundhedsministeriet; 2010. Available from: http://www. retsinformation.dk/Forms/r0710.aspx?id=130455\#K18. Accessed May 20, 2012. Danish.

11. Perry N, Broeders M, de Wolf C, Tôrnberg S, Holland R, von Karsa L. European guidelines for quality assurance in breast cancer screening and diagnosis. Fourth edition - summary document. Ann Oncol. 2008;19(4):614-622.

12. Frank L. Epidemiology. When an entire country is a cohort. Science. 2000;287(5462):2398-2399.

13. Danish Breast Cancer Cooperative Group. Guidelines Concerning Diagnosis. Copenhagen: Danish Breast Cancer Cooperative Group; 2011. Available from: http://www.dbcg.dk/PDF\%20Filer/Kap\%202\%20 Diagnose\%2027.04.11.pdf. Accessed May 20, 2012.

14. [Danish Quality Database of Mammography Screening]. DKMS Report 2010. The report can be obtained by contacting the Danish Regional Clinical Quality Program (RKKP): http://www.rkkp.dk/kontakt. Accessed February 7, 2013.

15. Erichsen R, Lash TL, Hamilton-Dutoit SJ, Bjerregaard B, Vyberg M, Pedersen L. Existing data sources for clinical epidemiology: the Danish National Pathology Registry and Data Bank. Clin Epidemiol. 2010;2: $51-56$. 
16. Andersen TF, Madsen M, Jørgensen J, Mellemkjoer L, Olsen JH. The Danish national hospital register. A valuable source of data for modern health sciences. Dan Med Bull. 1999;46(3):263-268.

17. Jensen AR, Overgaard J, Storm HH. Validity of breast cancer in the Danish Cancer Registry. A study based on clinical records from one county in Denmark. Eur J Cancer Prev. 2002;11(4):359-364.
18. Tvedskov TF, Jensen MB, Balslev E, Ejlertsen B, Kroman N. Stage migration after introduction of sentinel lymph node dissection in breast cancer treatment in Denmark: a nationwide study. Eur J Cancer. 2011; 47(6):872-878.

\section{Publish your work in this journal}

Clinical Epidemiology is an international, peer-reviewed, open access journal focusing on disease and drug epidemiology, identification of risk factors and screening procedures to develop optimal preventative initiatives and programs. Specific topics include: diagnosis, prognosis, treatment, screening, prevention, risk factor modification, systematic

Submit your manuscript here: http://www.dovepress.com/clinical-epidemiology-journal

\section{Dovepress}

reviews, risk \& safety of medical interventions, epidemiology \& biostatical methods, evaluation of guidelines, translational medicine, health policies \& economic evaluations. The manuscript management system is completely online and includes a very quick and fair peer-review system, which is all easy to use. 